\title{
FUNCTIONAL SYNAPSE ELIMINATION IN THE DEVELOPING AVIAN COCHLEAR NUCLEUS WITH SIMULTANEOUS REDUCTION IN COCHLEAR NERVE AXON BRANCHING ${ }^{1}$
}

\author{
HUNTER JACKSON ${ }^{2}$ AND THOMAS N. PARKS \\ Department of Anatomy, University of Utah School of Medicine, Salt Lake City, Utah 84132
}

Received March 22, 1982; Revised May 26, 1982; Accepted May 26, 1982

\begin{abstract}
We studied the chick auditory system to determine whether there is a normal developmental reduction in the number of cochlear nerve axons innervating individual cochlear nucleus (nucleus magnocellularis, NM) neurons. We also examined the preterminal branching patterns of cochlear nerve axons during development. The number of cochlear nerve axons innervating individual NM neurons was estimated by counting the increments in the postsynaptic response as the intensity of cochlear nerve electrical stimulation was varied gradually; this number fell from a mean of 4.0 on embryonic day 13 (E13) to a mean of 2.2 on E17 and E18 and the 4th day after hatching. This highly reliable decline in functional convergence was accompanied by a decrease in the number of preterminal branches of cochlear nerve fibers innervating the NM. On E13 and E14, most axons stained by iontophoretic injections of horseradish peroxidase showed two distinct preterminal branches in the NM. By E17 and E18 and thereafter, cochlear nerve axons were unbranched and terminated with a characteristic single large calycine ending in the NM. There are about twice as many cochlear nerve axons as neurons in the NM and the number of fibers in the nerve appears to decline only slightly between E13 and E17. The 50\% decline in the number of cochlear nerve axons making functional synapses on individual NM neurons therefore is associated principally with the concurrent elimination of cochlear nerve axon branching in the NM.
\end{abstract}

Developmental reductions in the number of axons innervating individual target cells have been documented at several sites in the peripheral nervous system (e.g., Brown et al., 1976; Johnson and Purves, 1981; reviewed by Purves and Lichtman, 1980). In at least some instances, decreased terminal branching by afferent axons seems to underlie this "synapse elimination" (e.g., Korneliussen and Jansen, 1976; Riley, 1977). A similar reduction in axonal convergence and branching may be involved in the progressive refinement of neuronal connections during the development of the central nervous system (CNS) (e.g., Crepel et al., 1980; Innocenti and Caminiti, 1980; Ivy et al., 1979; LeVay et al., 1978; Price et al., 1976; Rakic, 1976, 1977; So et al., 1978). However, there has been only one direct and unambiguous demonstration of a normal developmental decrease in functional axonal convergence onto a central neuron; Crepel et al. $(1976,1981)$ and Mariani and Changeux (1981) have

\footnotetext{
${ }^{1}$ This work was supported by Grant NS 17257 from the Public Health Service. We thank Patricia Collins for skillful tcchnical help. A preliminary report was given at the 95th Annual Meeting of the American Association of Anatomists, Indianapolis, April, 1982.

${ }^{2}$ To whom correspondence should be addressed.
}

reported decreased climbing fiber input onto developing rat Purkinje cells, but it is still unclear whether the elimination of inputs to these cells is associated with a reduction in the terminal fields of climbing fibers (Dupont et al., 1981). Alternative explanations (for example, a normal reduction in the number of afferent neurons) must be considered. Thus, it remains to be seen whether developmental "synapse elimination" is a general phenomenon in the CNS and, if so, whether it is accompanied by reductions in afferent axon terminal arbors.

The avian brain stem auditory system offers a number of advantages for directly addressing these developmental questions. The homogeneous group of adendritic or parvodendritic spherical neurons that constitute the avian nucleus magnocellularis (NM) receives large calycine end bulbs from the cochlear division of the eighth cranial nerve (Jhaveri and Morest, 1982a; Parks, 1981b; Parks and Rubel, 1978); each mature NM neuron receives only a small number of such endings (Hackett et al., 1982; Jhaveri and Morest, 1982a). The normal anatomical and functional organization of these neurons is well understood (Hackett et al., 1982; Jhaveri and Morest 1982a; Parks, 1981b; Parks and Rubel, 1975; Rubel and Parks, 1975) as are many aspects of their normal development 
(Conlee and Parks, 1982; Jackson et al., 1982; Jhaveri and Morest, 1982b, c; Parks, 1979; Rubel et al., 1976). Moreover, these neurons are accessible for study in an in vitro preparation during relevant stages of development (Jackson et al., 1982).

In this paper, we report the results of an electrophysiological analysis of cochlear nerve convergence onto NM neurons during normal development combined with an anterograde horseradish peroxidase labeling study, in the same animals, of cochlear nerve afferents in NM.

\section{Materials and Methods}

In vitro preparation. Embryos were removed from their shell and perfused transcardially with $15 \mathrm{ml}$ of cold $\left(4^{\circ} \mathrm{C}\right)$ oxygenated $\left(95 \% \mathrm{O}_{2}, 5 \% \mathrm{CO}_{2}\right)$ avian Tyrode's solution (139 mM NaCl, $17 \mathrm{~mm} \mathrm{NaHCO}, 3 \mathrm{~mm} \mathrm{KCl,} 1 \mathrm{~mm}$ $\mathrm{MgCl}, 3 \mathrm{~mm} \mathrm{CaCl}$, and $12.2 \mathrm{~mm}$ glucose, $\mathrm{pH}$ 7.3). Hatchling subjects were anesthetized with Ketalar $(350 \mathrm{mg} / \mathrm{kg}$, i.m.) prior to perfusion. The head then was submerged in a dissecting dish containing oxygenated Tyrode's solution at $2^{\circ} \mathrm{C}$. The brain was removed and the cerebellum was cut off at the peduncles. Finally, the brain stem was isolated by two oblique cuts between the cerebellar peduncles and the tecta. The brain stem then was placed on a small square of Telfa gauze backing and transferred to the recording chamber. The ventral surface of the tissue was fixed to the bottom of the chamber with a drop of cyanoacrylate glue.

Electrophysiology. Brain stems were superfused with oxygenated Tyrode's solution at room temperature (21 to $23^{\circ} \mathrm{C}$ ) during recording. The $\mathrm{Ca}^{2+}$ concentration in the superfusate was increased to $8 \mathrm{~mm}$ to improve the quality of impalements. The cochlear nerve was stimulated with a small (0.3-mm-wide) bipolar $\mathrm{Ag} / \mathrm{AgCl}$ electrode (0.065msec pulses, 0 to $25 \mathrm{~V}$, delivered at $0.3 \mathrm{~Hz}$ ). At the beginning of each recording session, field potentials representing the cochlear nerve volley, postsynaptic currents in the NM, and postsynaptic currents in the nucleus laminaris (NL) were recorded with $3 \mathrm{M}$ potassium acetate electrodes (10 to 15 megohms) (see Hackett et al., 1982). The latencies of these potentials helped to identify the source of intracellular potentials.

Data from 119 NM neurons were used in the present study. Electrodes filled with either $3 \mathrm{M}$ potassium acetate (70 to 120 megohms) or $0.5 \mathrm{M} \mathrm{KCl}, 4 \%$ horseradish peroxidase (HRP), and $0.05 \mathrm{M}$ Tris buffer ( $\mathrm{pH} 7.0 ; 100$ to $150 \mathrm{megohms}$ ) were used for intracellular recording. Occasional intra- and extracellular iontophoretic injections of HRP were made to verify further the source of intracellular potentials judged to be recorded from NM neurons on the basis of latency and position; these HRP deposits (12 intracelluar and 4 extracellular) were invariably located within the NM (see Fig. 1).

The NM excitatory postsynaptic potential (EPSP), produced by activation of cochlear nerve synapses and recorded from every penetrated NM cell, is characterized by a very fast rise time and short duration. A second type of PSP, apparently also depolarizing but having a longer latency, slower rise time, and longer duration, is recorded in about $10 \%$ of NM neurons (see Hackett et al., 1982). The source of this second type of PSP is unknown. These two types of PSPs are readily and unequivocally distin-

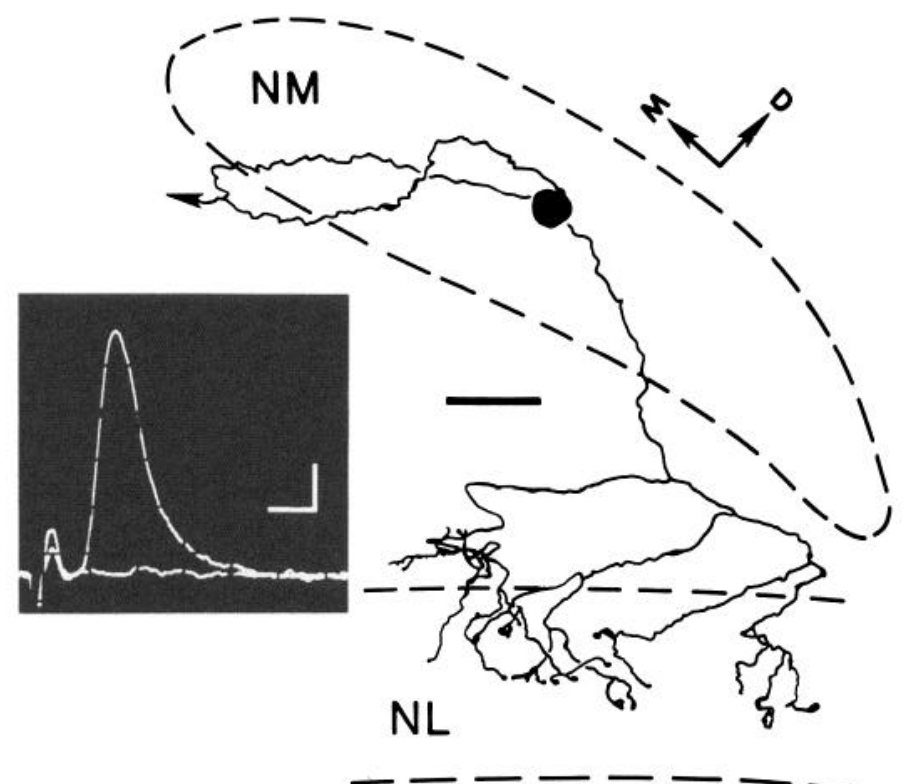

Figure 1. Camera lucida drawing (reconstructed from four $60-\mu \mathrm{m}$ sections) of an embryonic day 18 (E18) NM neuron injected with HRP. The axon initially courses ventromedially and then branches, sending one collateral (arrow) to the contralateral nucleus laminaris (NL). The other collateral passes back dorsolaterally to end in the dorsal neuropil of the ipsilateral NL. Bar, $50 \mu \mathrm{m}$. The inset shows an intracellular record from the labeled cell taken prior to the HRP injection. Calibration, $5 \mathrm{mV}, 2$ msec.

guishable. Only the components of the "fast" EPSP, mediated by cochlear nerve afferents, were analyzed in this study. The number of cochlear nerve axons innervating a given NM neuron was estimated by counting the number of discrete steps seen in the EPSP when stimulus intensity was changed gradually. Data from a particular cell were included in the present study only if the same steps were recorded during repeated sweeps of stimulus intensity. This criterion could not be met unless the membrane potential remained stable during these sweeps. Resting potentials were typically -40 to $-60 \mathrm{mV}$ upon impalement and subsequently stabilized at -25 to $-70 \mathrm{mV}$. Frequently, cells would stabilize at a given resting potential, later deteriorate to a somewhat lower potential, and stabilize for a time at that level. Repeated measurements under these circumstances clearly showed that the number of components seen in the EPSP was not dependent on resting potential. When action potentials obscured the components of the underlying EPSP for the duration of the impalement, data from that cell were not included in our analysis.

The possible limitations of this method of determining the number of afferents converging on individual target cells have been discussed previously (e.g., Lichtman and Purves, 1980; Lichtman, 1977, 1980; Purves and Hume, 1981). It should be reiterated, however, that this method provides a minimum estimate of convergence. Particularly at the younger ages studied, convergence of several afferents occasionally made it difficult to distinguish small increments in the EPSP or to differentiate components closely related in threshold. In 7 of 21 cells 


\section{IMMATURE}
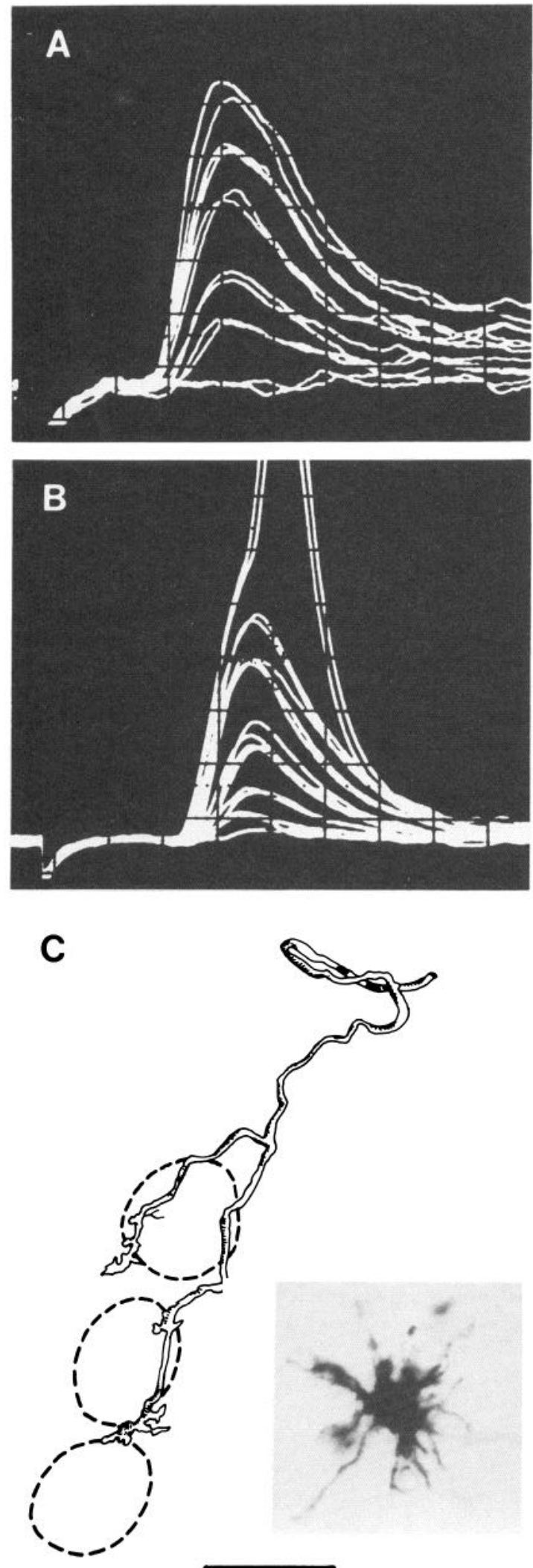

MATURE
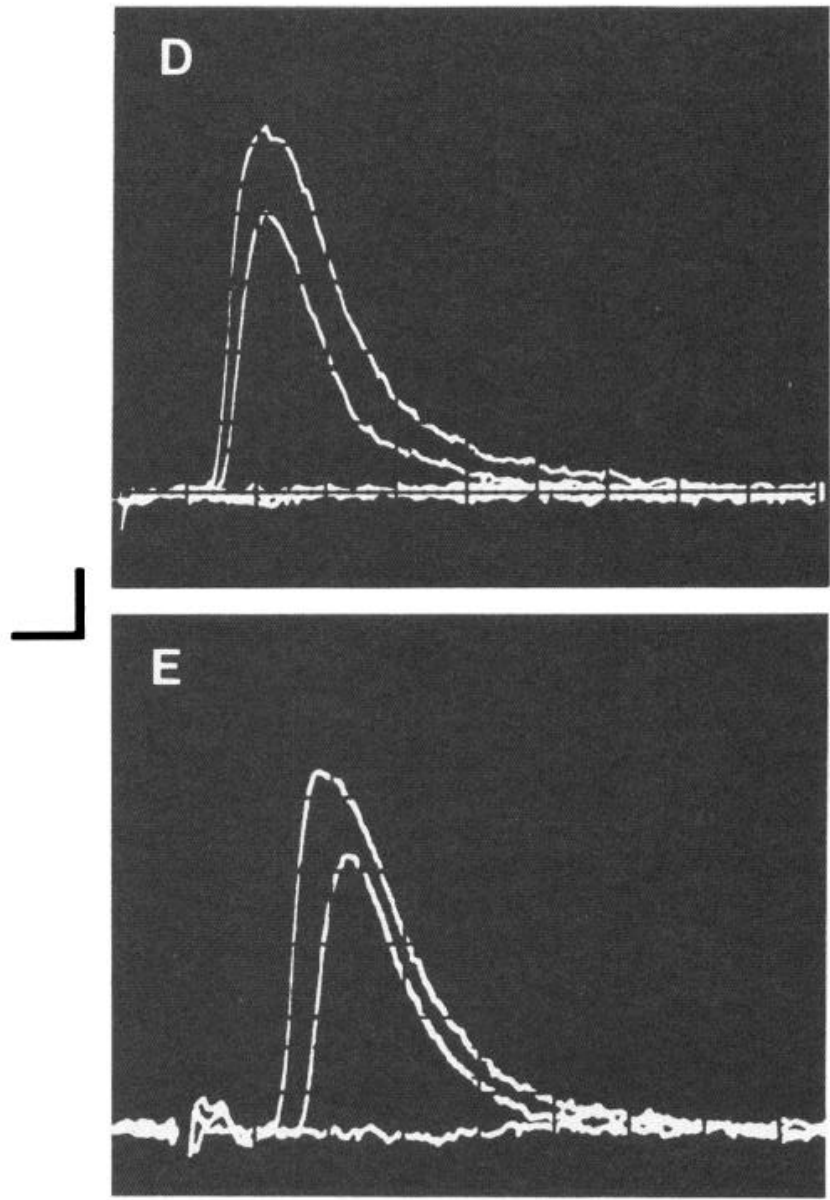

$\mathbf{F}$

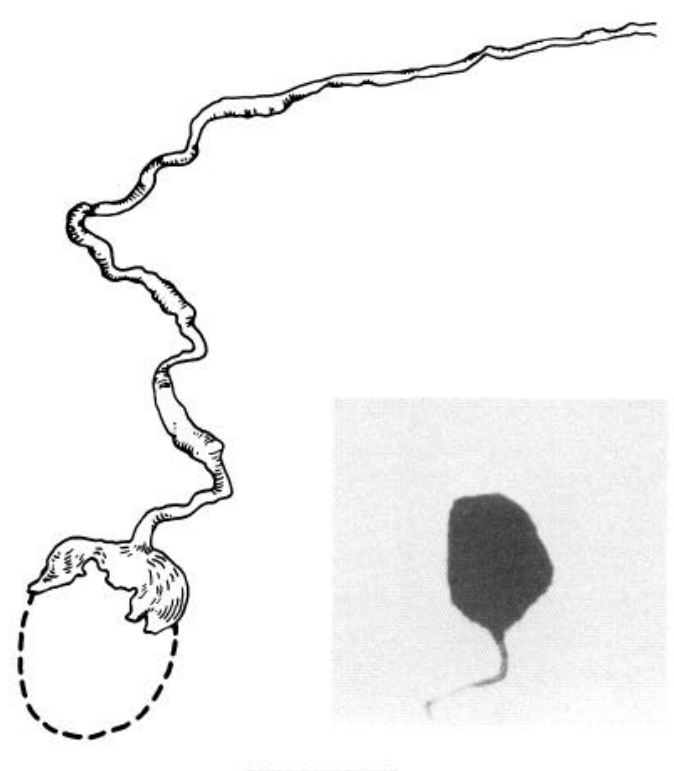

Figure 2. This figure illustrates the developmental reduction in the number of cochlear nerve axons innervating individual NM neurons and the corresponding reduction in terminal branching of cochlear nerve axons. $A$, Intracellular record from an NM neuron at E13. Gradual variation of cochlear nerve stimulus intensity revealed 5 components in this EPSP. Several traces are superimposed to show the unitary nature and reproducibility of the components upon repeated sweeps of stimulus intensity. $B$, Record from an NM neuron at E13 taken from a different preparation from that shown in $A$. At least 6 EPSP components and an action potential can be seen in this record. Traces generated during repeated sweeps of stimulus intensity are shown. $C$, Camera lucida drawing of an HRP-labeled cochlear nerve axon at E14. Note the terminal branching of the axon within the NM. 
sampled at embryonic day 13 (E13), for example, only a minimum number of components (usually 5 or 6 ) was scored because possible additional components could not be distinguished unequivocally.

One possible source of bias which must be considered is the adequacy of cochlear nerve stimulation at different ages. Our results might be artifactual if fewer afferent fibers were systematically stimulated in older subjects. However, the intensity of stimulation required to evoke maximum cochlear nerve and NM field potentials as well as maximum postsynaptic potentials in NM neurons was typically somewhat lower in older subjects than in younger ones. This is not surprising given the myelination and increase in diameter of cochlear nerve axons during this period. There is, therefore, no reason to suspect that cochlear nerve fibers were stimulated more effectively in younger subjects.

Finally, it is conceivable that the large number of components seen in EPSPs from younger neurons reflects, at least in part, electrical coupling between NM cells. Since individual NM cells cannot be seen in this preparation, it is impossible to perform the appropriate current-passing experiments on adjacent cells. However, electron micrographic studies of NM development from embryonic day 12 (E12) to posthatch day 60 (P60) have consistently failed to find any evidence of specialized membrane contacts between cells (Jhaveri and Morest, 1982c; T. N. Parks, unpublished observations), and the intracellularly recorded evoked responses to cochlear nerve stimulation show no signs of electrical coupling potentials (see also Hackett et al., 1982).

Anatomy. To label cochlear nerve axons and their endings in the NM, small iontophoretic injections of HRP were made into the nerve lateral to the NM. Microelectrodes were filled with a solution of $4 \% \mathrm{HRP}$ (Sigma type VI) and $0.5 \mathrm{M} \mathrm{KCl}$ in $0.1 \mathrm{M}$ Tris- $\mathrm{HCl}$ buffer at pH 7.0; resistances ranged from 20 to 40 megohms. While stimulating the cochlear nerve as described above, the recording electrode was advanced ventrally at the lateral edge of the brain stem. When the cochlear nerve afferent volley (see Hackett et al., 1982) was recorded, HRP was iontophoresed for 1 to $3 \mathrm{~min}$ using $150-\mathrm{msec}, 1$ to $2-\mu \mathrm{A}$ positive current pulses delivered at $1 \mathrm{~Hz}$. Fifteen minutes to $1 \mathrm{hr}$ was allowed for transport of the enzyme before fixation.

The labeled brain stems were fixed by immersion for 3 to $4 \mathrm{hr}$ in 3 to $5 \%$ glutaraldehyde in $0.1 \mathrm{M}$ phosphate buffer at $4^{\circ} \mathrm{C}$, rinsed briefly in the buffer, and then stored overnight in the buffer with $30 \%$ sucrose added. On the next day, $60-\mu \mathrm{m}$ coronal sections through the cochlear nuclei were cut on a freezing microtome. These sections were reacted for HRP by the cobalt-intensified diaminobenzidine method of Adams (1981), dehydrated, cleared, and coverslipped. Drawings of HRP-labeled cochelar nerve axons were made using a Zeiss camera lucida and $\times 63$ or $\times 100$ semiapochromatic objectives (numerical apertures, 1.26 and 1.30) at total magnifications of $\times 850$ to $\times 1,740$.

\section{Results}

Electrophysiology. Several quantitative developmental changes in NM postsynaptic potentials were observed in the course of this study. The latency of the responses decreased from about $5 \mathrm{msec}$ at E13 to 2 to 2.5 msec at P4. Conversely, the rate of rise of NM EPSPs increased markedly over this period. Finally, EPSP summation appeared to be considerably more linear at the younger ages studied. These developmental trends are apparent in Figure 2. The focus of this study, however, was the number of discrete components comprised by the composite EPSP and, by inference, the number of axons innervating individual NM neurons at various developmental stages.

Counts of discrete steps in the composite EPSP evoked by cochlear nerve stimulation were obtained from 119 NM neurons in a total of 31 preparations. The frequency distribution of EPSPs with various numbers of components is shown in Figure 3 for each age sampled. Progressing from E13 to $\mathrm{P} 4$, the peak of the distribution shifts downward from 4 to about 2 . Cells with 5 or more components were not seen after E15 and those with only 1 component were not seen before this age. As indicated on these histograms, the mean values at each age (taking each cell as an individual observation) fell from 4.0 at $\mathrm{E} 13$ to 2.58 at E15 and 2.2 at $\mathrm{P} 4$.

It was of interest to know if this trend is statistically significant and if the values for individual age groups might be compared reliably. The most appropriate tests for these data are the Cochran-Mantel-Haenzel $\chi^{2}$ procedure (Landis et al., 1978) and the Fisher exact test. To apply these analyses to the present data, a single mean number of EPSP components was calculated from all of the NM recordings in each preparation. These individual preparation means were used to determine the age group grand means shown on the left in Table 1A and the frequency scores in the contingency table also shown in Table $1 \mathrm{~A}$. The resulting $\chi^{2}$ value is very highly significant $(p<0.0001)$ and indicates that the relationship between increasing age and decreasing number of components is a strong and reliable one. This conclusion is bolstered by the results of an overall Fisher exact test. In this case, individual preparation means were categorized according to whether they fell above or below the median value (3.0) for the entire population of such means; the relationship between age and number of components again was found to be highly significant ( $p=0.00001$; twotailed test). The Fisher exact test also can be used to evaluate differences between individual age groups (see Table 1B). E13 embryos were found to differ significantly from E15, E17 and E18, and P4 preparations, whereas E14 embryos differ from E17 and E18 and P4 groups. No other individual age groups differ significantly, but this

The inset photomicrograph shows an E13 NM neuron stained by the Golgi-Cox method; note the numerous long somatic processes. Bar, $20 \mu \mathrm{m}$ for line drawing; $40 \mu \mathrm{m}$ for photomicrograph. $D$, Record from an NM neuron at P4, showing only 2 EPSP components. $E$, Record from an NM neuron at E18, again indicating innervation by only two cochlear nerve axons. $F$, Drawing of a labeled cochlear nerve fiber at P4. No terminal branches were seen at this age; individual axons terminated in the characteristic calycine ending apposed to a single NM neuron. The inset photomicrograph shows an E17 NM neuron stained by the Golgi-Rio Hortega method; note the complete absence of somatic processes. Bar, $20 \mu \mathrm{m}$ for line drawing; $24 \mu \mathrm{m}$ for photomicrograph. Calibration for electrophysiological records, $2 \mathrm{mV}, 2 \mathrm{msec}$ in $A ; 5 \mathrm{mV}, 2 \mathrm{msec}$ in $B, D$, and $E$. 
fact must be interpreted in light of the relatively small number of observations available in the two-age-group comparisons. The statistical analyses confirm the reliability of the developmental decline in EPSP component number and indicate that this process is substantially complete by E15.

Horseradish peroxidase labeling. The HRP injection sites were invariably located in the medial branch of the cochlear nerve lateral to the NM. About 5 to 30 nerve fibers were labeled at the injection sites although, particularly in the larger injections, not all individual fibers could be traced to their termination in the NM. In most cases, heavily labeled axons could be traced for 200 to $500 \mu \mathrm{m}$ from injection sites in the nerve to their endings on cells in the rostral two-thirds of the NM.

An example of the morphology of HRP-labeled cochlear nerve axons in E13 and E14 embryos is shown in Figure $2 C$. These axons typically had two distinct preterminal branches ending in lamellate swellings of variable size. At E14, these branches rarely extended over more than a few cell body diameters and seemed to show a slight preference for ramification along the dorsoventral axis of the NM. Although there was considerable variability in the morphology of HRP-filled axons at E13 and E14, virtually every fiber examined had two or more distinct terminal swellings adjacent to 2 or more NM cells. Whereas many axons had two distinct preterminal branches, there were some fibers with several swellings but no unequivocally distinct branches and rare axons with three short branches.

In E17 and E18 and P4 animals, no branches were seen in any of the labeled cochlear nerve axons; each of these axons coursed through the NM to end in a large calycine terminal on a single NM cell (see Fig. $2 F$ ). No morphological specializatiuns consistent with en passant junctions were seen in any of these labeled axons. The morphological transformation seen in HRP-labeled cochlear nerve fibers between E14 and E17 closely parallels that found by Jhaveri and Morest (1982b) in Golgi material.

\section{Discussion}

Structural basis of synapse elimination. Between E13 and $\mathrm{E} 17$, we found a $50 \%$ decrease in the number of cochlear nerve axons innervating individual NM neurons. In parallel with this decline in functional convergence, we also observed a reduction in the branching of cochlear nerve axons; at E14, these axons typically had two distinct preterminal branches within the NM, whereas at E17 and E18 and P4, every fiber ended in a single calycine terminal.

These results provide the first clear evidence from the CNS that a normal decline in afferent convergence onto individual target neurons occurs simultaneously with a developmental reduction in afferent-axon branching. Previous reports have shown that the number of climbing fibers innervating individual rat Purkinje cells declines during a circumscribed period in postnatal development (Crepel et al., 1976, 1981; Mariani and Changeux, 1981). However, recent attempts to relate this decline in functional convergence to concurrent changes in the size of climbing fiber terminal arbors have been unsuccessful (Dupont et al., 1981) and the possible role of cell death
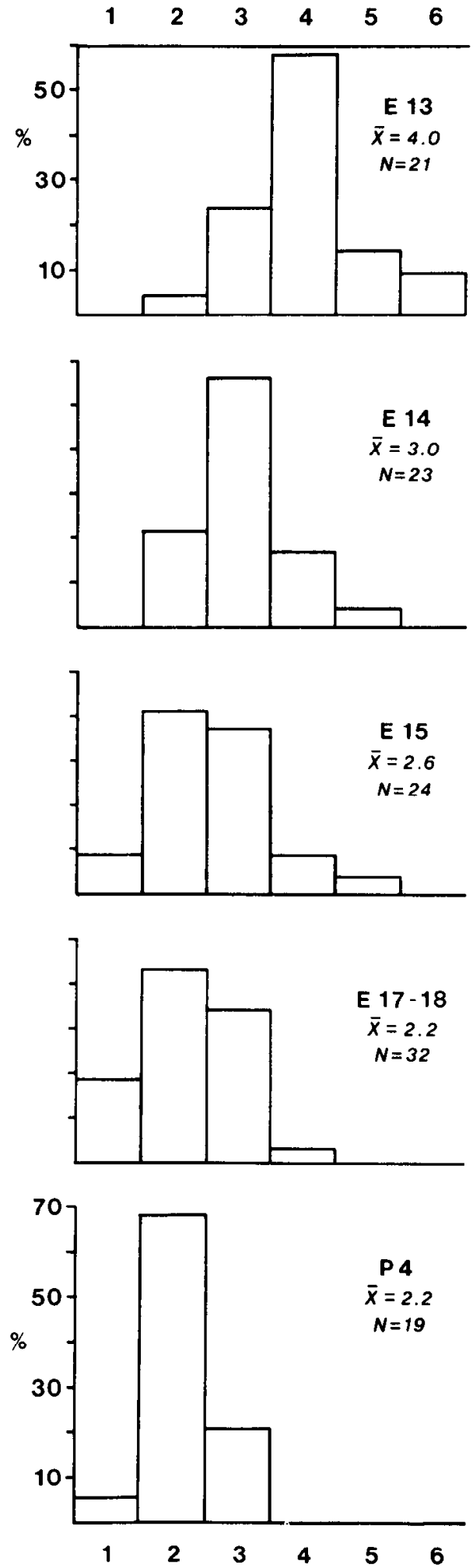

Figure 3. Frequency histograms showing the proportions of NM neurons receiving various numbers of cochlear nerve inputs at each age. The mean number of inputs found at each age also is shown as is the total number of NM cells from which we recorded.

in the inferior olivary nucleus remains unexplored (cf., Armstrong and Clarke, 1979; Caddy and Biscoe, 1979).

The possible role of normal cell death in explaining our results also must be considered. If the number of cochlear 
TABLE I

Statistical analyses of the EPSP component number in the nucleus magnocellularis (NM) at embryonic (E) and posthatching (P) ages The data are derived from 31 individual preparation means calculated from all of the NM recordings in each preparation. In Part A, on the left, the mean number of components at each age is shown. This is the grand mean of all individual preparation means for the given age. At the right part of $\mathrm{A}$, a contingency table gives for each age the number of preparation means which showed the number of EPSP components indicated by the column headings. A very highly reliable association between age and number of components was demonstrated with the Cochran-MantelHaenzel $\chi^{2}$ procedure: $Q-16.6 ; d f=1 ; p<0.00005$. In Part B, results of pairwise comparisons of the number of EPSP components in cach age group using the one-tailed Fisher exact test are given. The preparation means were categorized according to whether they fell below or above the median number of components (3.0) for all such means. Significant differences indicate that the number of EPSP components in the older group is reliably smaller than that in the younger group.

\begin{tabular}{|c|c|c|c|c|c|c|c|c|c|c|c|}
\hline \multicolumn{6}{|c|}{$\mathrm{A}$} & & \multicolumn{5}{|c|}{ B } \\
\hline \multirow{2}{*}{$\begin{array}{l}\text { Preparation } \\
\text { Mean }\end{array}$} & \multirow{2}{*}{ Age } & \multicolumn{4}{|c|}{ Number of Components } & & \multirow{2}{*}{ E13 } & \multirow{2}{*}{ E14 } & \multirow{2}{*}{ E15 } & \multirow{2}{*}{ E17-18 } & \multirow{2}{*}{$\mathrm{P}_{4}$} \\
\hline & & $1.5-2.49$ & $2.5-3.49$ & $3.5-4.49$ & $4.5-5.59$ & & & & & & \\
\hline 3.25 & E14 & 0 & 6 & 0 & 1 & E17-18 & $p<0.005$ & $p<0.005$ & ns & & \\
\hline 2.80 & E15 & 1 & 3 & 1 & 0 & E15 & $p<0.05$ & $\cdot \mathrm{ns}$ & & & \\
\hline 2.16 & E17-18 & 5 & 1 & 0 & 0 & E14 & $\mathrm{ns}$ & & & & \\
\hline
\end{tabular}

${ }^{a} \mathrm{~ns}$, not significant.

nerve fibers declined by $50 \%$ between $\mathrm{E} 13$ and E17, the electrophysiological results could be explained without involving any of the observed changes in axonal branching. This possibility is very unlikely. Ard and Morest (1981) counted the number of cochlear ganglion cells in chick embryos on E8 and P14 and found a statistically significant decline of only $18 \%$ over this period. Much of this loss may occur before E13 and E14. Given a small normal decline in the number of NM neurons during this period (Rubel et al., 1976), the relative number of cochlear nerve axons per NM cell (about 2:1) probably changes little during development. It thus seems most unlikely that a normal loss of cochlear nerve axons can be responsible for more than a small fraction of the decline in afferent convergence on individual NM targets.

The present electrophysiological results appear to be supported adequately by the observations that (1) the number of cochlear ganglion cells innervating the NM appears to remain relatively constant at about 8,000 to 9,000 (Ard and Morest, 1981; T. N. Parks and H. Jackson, unpublished observations), (2) the number of NM neurons at E13 to P4 is about 4,200 (Rubel et al., 1976; Parks, 1979), and (3) cochlear nerve fibers have an average of two branches in the NM at E13 and E14 but only a single ending from E17 onward. Thus, at E13, with an average of two branches on each cochlear nerve fiber in the NM, there are probably about 17,000 functional endings available to form synapses on 4,200 NM neurons; this ratio of about four different axon branches innervating each NM neuron is quite close to the average of 4.0 discrete EPSP components per cell at this stage found in the present study. After E17, when each cochlear nerve fiber has a single ending, there would be about a $2: 1$ ratio of axons to target cells, and this is, in fact, quite close to our observed E17 and E18 and P4 values.

Relationship to target cell geometry. There is a close temporal correspondence between the reduction of the number of axons innervating individual NM cells and the dramatic changes in the geometry of those cells. Beginning at about E10, NM neurons sprout a profusion of somatic processes (Jhaveri and Morest, 1982b). It is likely that this corresponds to an early stage of synapse formation between cochlear nerve axons and NM cells in that synaptically evoked extracellular responses to cochlear nerve stimulation can first be recorded from a small number of NM neurons at E11 (Jackson et al., 1982). Electron microscopy at E13 (the earliest age studied by Jhaveri and Morest, 1982c) reveals that immature synapses are formed by cochlear nerve fibers on NM somatic processes; synaptic contacts on the soma of NM cells are rare at this stage. The somatic processes are maintained through E13 and into E14, but by E15, they become shorter and less profuse. By E17, the processes have all but disappeared, leaving most NM cells adendritic (see Fig. 2; Conlee and Parks, 1982; Jhaveri and Morest, 1982a). As somatic processes are lost, cochlear nerve terminals are transformed gradually into the large calycine end bulbs apposed to the target cell soma. The loss of somatic processes and the shift in the position of synapses may be responsible for the apparent developmental increase in the nonlinearity of EPSP summation (e.g., Fig. 2; cf., Rall, 1967).

Cochlear nerve synapses are formed initially on NM somatic processes; the loss of some of these contacts and the reduction in the number of axons innervating individual NM cells parallel the loss of somatic processes between E14 and E17. The progressive reduction in the number of inputs and coincident simplification of target cell geometry resembles the findings of Purves and Hume (1981), who reported a direct relationship between the number of axons innervating individual adult rabbit ciliary ganglion cells and the complexity of the cell's dendritic arbor. Experimental results suggest that the issuance and loss of the NM somatic processes occur independently of cochlear nerve afferents. Surgical ablation of the otocyst after 50 to $60 \mathrm{hr}$ of incubation prevents the formation of the inner ear and cochlear nerve. In the absence of these structures, NM cells sprout somatic processes by E11 and these processes are lost by E17 (Parks, 1981a). This finding implies that the normal loss of processes does not result from a developmental reduction in afferent convergence; rather, it seems likely that it is the loss of somatic processes which leads to an elimination of some inputs to the target. On the basis of cell-by-cell correlations between the complexity of target cell dendritic arbors and the number of afferent inputs, 
Hume and Purves (1981) similarly concluded that target cell geometry determines the number of functionally similar inputs that can maintain synapses on that cell.

The present results, taken together with those of Parks (1981a) and Hume and Purves (1981), suggest that the transient somatic processes issued by NM neurons serve the function of allowing synapses from several cochlear nerve axons to form on individual target cells. This would help to insure adequate innervation of NM cells and provide a basis for the subsequent selection of the most "appropriate" inputs. This selection process would be fostered by the gradual elimination of processes, which would force the various inputs to compete for some as yet unidentified factor related to postsynaptic space or "domains" (see Purves and Hume, 1981).

\section{References}

Adams, J. C. (1981) Heavy metal intensification of DAB-based IIRP reaction product. J. Histochem. Cytochem. 29: 775.

Ard, M. D., and D. K. Morest (1981) Role of peripheral target in development of sensory neurons. Soc. Neurosci. Abstr. 7: 768.

Armstrong, R. C., and P. G. Clarke (1979) Neuronal death and the development of the pontine nuclei and inferior olive in the chick. Neuroscience 4: 1635-1647.

Brown, M. C., J. K. S. Jansen, and D. Van Essen (1976) Polyneuronal innervation of skeletal muscle in new-born rats and its elimination during maturation. J. Physiol. (Lond.) 261: $387-422$.

Caddy, K. W., and T. J. Biscoe (1979) Structural and quantitative studies on the normal $\mathrm{C} 3 \mathrm{H}$ and Lurcher mutant mouse. Philos. 'Irans. R. Soc. Lond. (Biol.) 287: 167-201.

Conlee, J. W., and T. N. Parks (1982) Morphogenesis of dendrites in the avian nucleus magnocellularis: Normal development and the effects of monaural acoustic deprivation. Anat. Rec. 202: 35A.

Crepel, F, J. Mariani, and N. Delhaye-Bouchaud (1976) Evidence for a multiple innervation of Purkinje cells by climbing fibers in the immature rat cerebellum. J. Neurobiol. 7: 567-578.

Crepel, F., N. Delhaye-Bouchaud, J. L. Dupont, and C. Sotelo (1980) Dendritic and axonic fields of Purkinje cells in developing and X-irradiated rat cerebellum. A comparative study using intracellular staining with horseradish peroxidase. Neuroscience 5: 333-347.

Crepel, F., N. Delhaye-Bouchaud, and J. L. Dupont (1981) Fate of the multiple innervation of cerebellar Purkinje cells by climbing fibers in immature control, $\mathrm{X}$-irradiated, and hypothyroid rats. Dev. Brain Res. 1: 59-71.

Dupont, J. L., N. Delhaye-Bouchaud, and F. Crepel (1981) Autoradiographic study of the distribution of olivocerebellar connections during the involution of the multiple innervation of Purkinje cells by climbing fibers in the developing rat. Neurosci. Lett. 26: 215-220.

Hackett, J. T., H. Jackson, and E. W. Rubel (1982) Synaptic excitation of the second- and third-order auditory neurons in the avian brain stem. Neuroscience 7: 1455-1469.

Hume, R. I., and D. Purves (1981) Geometry of neonatal neurones and the regulation of symapse elimination. Nature 293: 469-471.

Innocenti, G. M., and R. Caminiti (1980) Postnatal shaping of callosal connections from sensory areas. Exp. Brain Res. 38: 381-394.

Ivy, G. O., R. M. Akers, and H. P. Killackey (1979) Differential distribution of callosal projection neurons in the neonatal and adult rat. Brain Res. 173: 532-537.
Jackson, H., J. T. Hackett, and E. W. Rubel (1982) Organization and development of the brain stem auditory nuclei in the chicken: Ontogeny of postsynaptic responses. J. Comp. Neurol. 210: $80-86$.

Jhaveri, S. R., and D. K. Morest (1982a) Neuronal architecture in nucleus magnocellularis of the chicken auditory system with observations on nucleus laminaris: A light and electron microscope study. Neuroscience 7: 809-835.

Jhaveri, S. R., and D. K. Morest (1982b) Sequential alterations of neuronal architecture in nucleus magnocellularis of the developing chick: A Golgi study. Neuroscience, 7: 837-853.

Jhaveri, S. R., and D. K. Morest (1982c) Sequential alterations of neuronal architecture in nucleus magnocellularis of the chicken: An electron microscope study. Neuroscience 7: 855870.

Johnson, D. A., and D. Purves (1981) Post-natal reduction of neural unit size in the rabbit ciliary ganglion. J. Physiol. (Lond.) 318: 143-159.

Korneliussen, H., and J. K. S. Jansen (1976) Morphological aspects of the elimination of polyneuronal innervation of skeletal muscle fibers in newborn rats. J. Neurocytol. 5: 591-604.

Landis, J. R., E. R. Heyman, and G. G. Koch (1978) Average partial association in three-way contingency tables: A review and discussion of alternative tests. Int. Statis. Rev. 46: 237-254.

LeVay, S., M. P. Stryker, and C. J. Shatz (1978) Ocular dominance columns and their development in layer IV of the cat's visual cortex: A quantitative study. J. Comp. Neurol. 179: 223-244.

Lichtman, J. W. (1977) The reorganization of synaptic connexions in the rat submandibular ganglion during post-natal development. J. Physiol. (Lond.) 273: 155-177.

Lichtman, J. W. (1980) On the predominantly single innervation of submandibular ganglion cells in the rat. J. Physiol. (Lond.) 302: 121-130.

Lichtman, J. W., and D. Purves (1980) The elimination of redundant preganglionic innervation to hamster sympathetic ganglion cells in early post-natal life. J. Physiol. (Lond.) 301: 213-228.

Mariani, J., and J. -P. Changeux (1981) Ontogenesis of olivocerebellar relationships. I. Studies by intracellular recordings of the multiple innervation of Purkinje cells by climbing fibers in the developing rat cerebellum. J. Neurosci. 1: 696-702.

Parks, T. N. (1979) Afferent influences on the development of the brain stem auditory nuclei of the chicken: Otocyst ablation. J. Comp. Neurol. 183: 665-678.

Parks, T. N. (1981a) Development of three brain stem auditory nuclei after unilateral surgical ablation of the otocyst in chick embryos. In Abstracts of the 4th Midwinter Meeting of the Association for Research in Otolaryngology, p. 41, Association for Research in Otolaryngology, St. Petersburgh Beach.

Parks, T. N. (1981b) Morphology of axosomatic endings in an avian cochlear nucleus: Nucleus magnocellularis of the chicken. J. Comp. Neurol. 203: 425-440.

Parks, T. N., and E. W. Rubel (1975) Organization and development of the brain stem auditory nuclei of the chicken: Organization of projections from nuc. magnocellularis to nuc. laminaris. J. Comp. Neurol. 164: 435-448.

Parks, T. N., and E. W. Rubel (1978) Organization and development of the brain stem auditory nuclei of the chicken: Primary afferent projections. J. Comp. Neurol. 180: 439-448.

Price, J. L., G. F. Moxley, and J. E. Schwob (1976) Development and plasticity of complementary afferent fiber systems to the olfactory cortex. Exp. Brain Res. Suppl. 1: 148-154.

Purves, D., and R. I. Hume (1981) The relation of postsynaptic geometry to the number of presynaptic axons that innervate autonomic ganglion cells. J. Neurosci. 1: 441-452. 
Purves, D., and J. W. Lichtman (1980) Elimination of synapses in the developing nervous system. Science 210: 153-157.

Rakic, P. (1976) Prenatal genesis of connections subserving ocular dominance in the rhesus monkey. Nature 261: 467-471.

Rakic, P. (1977) Prenatal development of the visual system in rhesus monkey. Philos. Trans. R. Soc. Lond. (Biol.) 278: 245-260.

Rall, W. (1967) Distinguishing theoretical synaptic potentials computed for different soma-dendritic distributions of synaptic input. J. Neurophysiol. 30: 1138-1168.

Riley, D. (1977) Spontaneous elimination of nerve terminals from the end-plates of developing skeletal myofibers. Brain
Res. 134: 279-285.

Rubel, E. W., and T. N. Parks (1975) Organization and development of the brain stem auditory system of the chicken: Tonotopic organization of nuc. magnocellularis and nuc. laminaris. J. Comp. Neurol. 164: 411-434.

Rubel, E. W., D. J. Smith, and L. C. Miller (1976) Organization and development of the brain stem auditory nuclei of the chicken: Ontogeny of nuc. magnocellularis and nuc. laminaris. J. Comp. Neurul. 166: 469-490.

So, K. -F., G. E. Schneider, and D. O. Frost (1978) Postnatal development of retinal projections to the lateral geniculate body in Syrian hamsters. Brain Res. 142: 343-352. 